\title{
Enhancing utilization of lithium metal electrodes in all-solid-state batteries by interface modification with gold thin films
}

\author{
Atsutaka Kato ${ }^{1}$, Akitoshi Hayashi ${ }^{1}$ and Masahiro Tatsumisago ${ }^{1}$ \\ ${ }^{1}$ Department of Applied Chemistry, Graduate School of Engineering, \\ Osaka Prefecture University, \\ 1- 1 Gakuen-cho, Naka-ku, Sakai, Osaka 599-8531, JAPAN
}

\section{*Corresponding author:}

Akitoshi Hayashi (Associate Professor)

Department of Applied Chemistry, Graduate School of Engineering,

Osaka Prefecture University,

1-1 Gakuen-cho, Naka-ku, Sakai, Osaka 599-8531, JAPAN

Tel.: +81-72-2549331; Fax.: +81-72-2549334

E-mail address: hayashi@chem.osakafu-u.ac.jp. 


\begin{abstract}
To evaluate ideal interfaces between $\mathrm{Li}$ metal and $\mathrm{Li}_{2} \mathrm{~S}-\mathrm{P}_{2} \mathrm{~S}_{5}$ solid electrolytes, bulk-type cells were fabricated using thin $\mathrm{Li}$ metal films prepared by vacuum-evaporation. The symmetric cell of $\mathrm{Li} / 75 \mathrm{Li}_{2} \mathrm{~S} \cdot 25 \mathrm{P}_{2} \mathrm{~S}_{5} / \mathrm{Li}$ showed a high utilization of $\mathrm{Li}$ metal (about 40\%), though abrupt decrease of the utilization was observed after 5 cycles. A high utilization of Li metal (about 25\%) was retained for 5 cycles by inserting $\mathrm{Au}$ thin film at the interface between $\mathrm{Li}$ metal and $\mathrm{Li}_{2} \mathrm{~S}-\mathrm{P}_{2} \mathrm{~S}_{5}$ solid electrolytes. Morphology of Li metal after dissolution/deposition cycles for the cell with Au thin film became more uniform compared to the cell without Au thin film.
\end{abstract}




\section{Introduction}

$\mathrm{Li}$ ion batteries have been widely used as electric power sources for mobile phones, laptops and other devices. However, the highest energy storage which the Li ion batteries can deliver is not enough to meet the increasing demands of markets such as electric vehicles with long-distance drive. To achieve higher energy density, Li metal is the most attractive material as a negative electrode because of its extremely high theoretical capacity (3861 $\mathrm{mAh} \mathrm{g}^{-1}$ ) and the lowest negative electrochemical potential (-3.04 V vs. SHE) [1]. However, dendrite growth and low coulombic efficiency during charging and discharging are a fatal problem for Li metal batteries using conventional organic liquid electrolytes. Dendrite growth leads to short-circuiting and increases the risk of fire [2]. The use of inorganic solid electrolytes in Li metal batteries is expected to solve the problem.

Li metal batteries using inorganic solid electrolytes are categorized to thin-film or bulk-type batteries. Thin-film batteries are prepared by accumulating solid electrolytes and electrode active materials on a plate by RF magnetron sputtering or vacuum-evaporation. These processes construct favorable interfaces between solid electrolytes and electrode active materials, including Li metal. Li metal batteries have achieved excellent cell performance in thin-film batteries [3-8]. Thin-film batteries 
using lithium phosphorous oxynitride (LiPON) as solid electrolytes show long cycle life over 40,000 times without the capacity fading [3]. However, energy storage in thin-film batteries is small because by using sputtering and vacuum-evaporation processes, it is difficult to accumulate a large amount of electrode active materials. On the other hand, bulk-type batteries are prepared by stacking solid electrolyte powders and composite electrode powders of electrode active materials and solid electrolytes by pressing [9]. Metal foils in place of the composite electrodes are used as metal electrodes such as $\mathrm{Li}$ electrodes. The bulk-type battery is expected to have larger energy storage due to the addition of larger amounts of active materials to the cell. However, at least three points should be improved to realize bulk-type Li metal batteries; the first improvement is $\mathrm{Li}$ ion conductivity of solid electrolytes, the second one is the chemical stability of solid electrolytes against $\mathrm{Li}$ metal electrode, and the third one is the interface condition between Li metal and solid electrolytes. For bulk-type batteries, it is difficult to form favorable interfaces between $\mathrm{Li}$ metal and solid electrolytes because grain boundaries and voids remain on the surface of solid electrolytes due to compression of the powders. Inhomogeneous interfaces are a serious issue for bulk-type batteries using $\mathrm{Li}$ metal electrode, forming inhomogeneous electrodeposition of $\mathrm{Li}$ metal during repeated charge-discharge cycles. 
We have developed sulfide-based solid electrolytes and reported that $\mathrm{Li}_{2} \mathrm{~S}-\mathrm{P}_{2} \mathrm{~S}_{5}$ solid electrolytes have high ionic conductivities $\left(>10^{-4} \mathrm{~S} \mathrm{~cm}^{-1}\right)$ and chemical stability against Li metal [10-11]. $\mathrm{Li}_{2} \mathrm{~S}-\mathrm{P}_{2} \mathrm{~S}_{5}$ solid electrolytes are a good candidate to realize bulk-type Li metal batteries. Meanwhile, the interface condition between Li metal and solid electrolytes is still insufficient in spite of less grain boundaries and voids of the sulfide electrolyte powders pressed at ambient temperature [12]. In our previous reports about bulk-type Li metal batteries, an abrupt potential change was observed for the batteries using a Li foil because of inhomogeneous interfaces between a Li foil and the electrolyte [13]. Our group also reported that favorable interfaces prepared by vacuum-evaporation of $\mathrm{Li}$ metal improved the reversibility of $\mathrm{Li}$ dissolution and deposition in bulk-type batteries. In addition, we and other researchers have suggested that insertion of a Li-alloy thin layer at the interface between $\mathrm{Li}$ electrode and solid electrolyte layers brought about a stable $\mathrm{Li}$ dissolution and deposition in the all-solid-state Li metal cells [14-16]. These interface modifications are effective in establishing homogeneous interfaces between Li metal and solid electrolytes.

To achieve high energy density in bulk-type Li metal batteries, investigations about utilization of $\mathrm{Li}$ metal are essential. Thin-film batteries such as $\mathrm{Li} / \mathrm{LiPON} / \mathrm{LiCoO}_{2}$ cells have shown excellent cycle performance. Because $\mathrm{Li} / \mathrm{LiPON} / \mathrm{LiCoO}_{2}$ cells use the 
lithiated positive electrode, the utilization of Li metal is not high. Bulk-type cells using metallic thin Li films prepared by vacuum-evaporation instead of Li foils are suitable to evaluate utilization of Li metal because the ideal interfaces between Li metal and solid electrolytes are formed. The bulk-type cells with Li thin films are not suitable for practical application because of the smaller amount of energy storage, but the cells will give many useful suggestions for upcoming bulk-type batteries using Li foils.

In this study, symmetric cells using metallic thin $\mathrm{Li}$ films were fabricated. Utilization of Li metal and the reversibility were investigated at the surface of the compressed-powder pellets of $\mathrm{Li}_{2} \mathrm{~S}-\mathrm{P}_{2} \mathrm{~S}_{5}$ solid electrolytes. Furthermore, $\mathrm{Au}$ which forms alloys with Li metal [17] was inserted as a thin film to the interface between $\mathrm{Li}$ metal and $\mathrm{Li}_{2} \mathrm{~S}-\mathrm{P}_{2} \mathrm{~S}_{5}$ solid electrolytes. Au thin film is often used as current collectors for measuring conductivities of sulfide solid electrolytes and therefore Au has a good compatibility with sulfides. The effects of the insertion of Au thin films prepared by vacuum-evaporation on Li dissolution and deposition behaviors were examined.

\section{Experimental}

Sulfide glasses at the composition of $75 \mathrm{Li}_{2} \mathrm{~S} \cdot 25 \mathrm{P}_{2} \mathrm{~S}_{5}(\mathrm{~mol} \%)$ were prepared by mechanical milling. The obtained powders were pelletized by pressing under pressure of 
$360 \mathrm{MPa}$ at ambient temperature. The diameter and thickness of the electrolyte pellets were about $10 \mathrm{~mm}$ and $0.76 \mathrm{~mm}$, respectively. In order to investigate electrochemical properties of $\mathrm{Li}$ dissolution and deposition, symmetric cells with $\mathrm{Li} / 75 \mathrm{Li}_{2} \mathrm{~S} \cdot 25 \mathrm{P}_{2} \mathrm{~S}_{5} / \mathrm{Li}$ configuration was fabricated. A Li thin film was formed by vacuum-evaporation on both sides of the electrolyte pellet. The active electrode area of all the cells was $0.785 \mathrm{~cm}^{2}$, which is the same as the diameter of electrolyte pellets. In order to investigate the effects of the insertion of $\mathrm{Au}$ thin film between $\mathrm{Li}$ metal and $\mathrm{Li}_{2} \mathrm{~S}-\mathrm{P}_{2} \mathrm{~S}_{5}$ solid electrolytes, Au thin film was also deposited by vacuum-evaporation before depositing Li films. A thermal evaporator (VPC-060, ULVAC, Inc.) placed in an Ar-filled glove box was used for preparation of $\mathrm{Li}$ and $\mathrm{Au}$ thin films. The obtained pellets after vacuum-evacuation of $\mathrm{Li}$ and $\mathrm{Au}$ films were sandwiched between two stainless-steels plates as a current collector. The pellets with current collectors were packed in an Ar-filled container. The electrochemical tests were conducted at $25^{\circ} \mathrm{C}$ using charge-discharge measuring devices (BTS-2004, Nagano Co.), whose lead wires were connected to the stainless-steel electrodes in the container. At first, the symmetric cells were worked at a negative potential direction and stopped when the cell potential reached to $-50 \mathrm{mV}$. After that, the cell operation was switched to a positive potential direction until an electrical quantity was the same as that obtained at the previous operation. As a result, the quantity of $\mathrm{Li}$ 
on both sides were unchanged after each cycle of Li dissolution and deposition. The current density for galvanostatic cycling tests was $0.064 \mathrm{~mA} \mathrm{~cm}^{-2}$. A resistance for the cells was measured by AC impedance using an impedance analyzer (Solartron, 1260) in the frequency range of from $0.1 \mathrm{~Hz}$ to $1 \mathrm{MHz}$. The morphologies of $\mathrm{Li}$ thin films on the electrolyte pellets were observed by a scanning electron microscope (SEM, JSM-6610A, JEOL).

\section{Results and discussion}

A SEM image for cross-section of the interface between a $\mathrm{Li}$ thin film and $\mathrm{Li}_{2} \mathrm{~S}-\mathrm{P}_{2} \mathrm{~S}_{5}$ solid electrolytes are shown in Fig. 1. The electrolyte pellet pressed at ambient temperature had some grain boundaries and voids on the surface as well as cross-section of the pellet. It is noted that the deposited Li thin film filled with the grain boundaries and voids on the surface of solid electrolytes, and thus good interfaces with contacts between $\mathrm{Li}$ metal and $\mathrm{Li}_{2} \mathrm{~S}-\mathrm{P}_{2} \mathrm{~S}_{5}$ solid electrolytes were obtained. The thickness of a $\mathrm{Li}$ thin film was about $3 \mu \mathrm{m}$. Therefore, the loading of Li metal was about $0.126 \mathrm{mg}$ calculated from the density of $\mathrm{Li}\left(6.941 \mathrm{~g} \mathrm{~cm}^{-3}\right)$.

Galvanostatic cycling tests for the $\mathrm{Li} / 75 \mathrm{Li}_{2} \mathrm{~S} \cdot 25 \mathrm{P}_{2} \mathrm{~S}_{5} / \mathrm{Li}$ cell are shown in Fig. 2. At the initial cycle, the Li dissolution/deposition time of the cell was about 4 hours (915 
$\mathrm{mC} \mathrm{cm}^{-2}$ ), which corresponds to about $0.0518 \mathrm{mg}$ of $\mathrm{Li}$ dissolution/deposition; the utilization of Li metal was thus about $40 \%$ calculated from the loading of Li metal. $40 \%$ of utilization of Li metal was higher than the utilization of Li metal for thin-film batteries (which was at most $20 \%$, calculated utilization based on the reference 5-8). High utilization of Li metal is demanded for practical Li metal batteries, and the cell with high utilization of Li metal meets the demand for batteries with a high energy density. However, utilization of Li metal for the cell decreased rapidly after 5 cycles.

Figure 3 shows impedance plots of the $\mathrm{Li} / 75 \mathrm{Li}_{2} \mathrm{~S} \cdot 25 \mathrm{P}_{2} \mathrm{~S}_{5} / \mathrm{Li}$ cell (a) before galvanostatic tests, and (b) after the tests at the negative potential direction (i) and at the positive potential direction (ii). These impedance plots showed that a cell resistance before galvanostatic tests was about $250 \Omega$ and increased largely after the initial galvanostatic tests at the negative potential side. The cell resistance decreased slightly after galvanostatic tests at the positive potential side and increased slightly after following galvanostatic tests at the negative potential side again. The cell resistance includes various kinds of resistance components. The resistance of a distorted semicircle with characteristic frequency of $250 \mathrm{kHz}$ is probably attributed to the interfacial resistance of $\mathrm{Li}$ metal and $\mathrm{Li}_{2} \mathrm{~S}-\mathrm{P}_{2} \mathrm{~S}_{5}$ solid electrolytes, and the resistance at the higher frequency region of the semicircle is attributed to the resistance of the electrolyte pellet. 
SEM images for cross-section and surface of the Li symmetric cell before and after galvanostatic cycling tests are shown in Fig. 4. The morphology of a Li thin film was rough after galvanostatic cycling tests, while the morphology of the Li thin film was flat before galvanostatic cycling tests. It is surprising that the morphology of $\mathrm{Li}$ metal changed drastically, though homogeneous interfaces were formed by vacuum-evaporation before galvanostatic tests. The drastic morphology change indicated that inhomogeneous $\mathrm{Li}$ dissolution/deposition reactions occurred during galvanostatic cycling tests. A rapid decrease of utilization of Li metal shown in Fig. 2 would be caused by the drastic morphology change of Li thin films. The drastic morphology change may be related to the generation of voids at the interface between $\mathrm{Li}$ metal and $\mathrm{Li}_{2} \mathrm{~S}-\mathrm{P}_{2} \mathrm{~S}_{5}$ solid electrolytes on the basis of "void generation" suggested by Kudo et al. [16]. The resistance change in Fig. 3 is well-explained by considering the generation and disappearance of voids at the interface between Li metal and $\mathrm{Li}_{2} \mathrm{~S}-\mathrm{P}_{2} \mathrm{~S}_{5}$ solid electrolytes. The generation of voids at the interface between $\mathrm{Li}$ metal and $\mathrm{Li}_{2} \mathrm{~S}-\mathrm{P}_{2} \mathrm{~S}_{5}$ solid electrolytes accelerates inhomogeneous $\mathrm{Li}$ dissolution/deposition reactions because uneven current distributions are caused at such voids. The morphology change of Li metal after 5 cycles may relate to the generation of voids and detail investigation is now under consideration. 
It is reported that a Li-alloy thin film (e.g., Li-In, Li-Bi and Li-Pt) [14-16] at the interface between $\mathrm{Li}$ metal and solid electrolytes is effective in achieving stable Li dissolution and deposition. In this study, an Au thin film was inserted at the interface between the $\mathrm{Li}$ thin film and $\mathrm{Li}_{2} \mathrm{~S}-\mathrm{P}_{2} \mathrm{~S}_{5}$ solid electrolytes. Figure 5 shows a $\mathrm{SEM}$ image for cross-section of the interface between the $\mathrm{Au}$ thin film and $\mathrm{Li}_{2} \mathrm{~S}_{-} \mathrm{P}_{2} \mathrm{~S}_{5}$ solid electrolytes. The Au thin film was adhesively formed on the $\mathrm{Li}_{2} \mathrm{~S}-\mathrm{P}_{2} \mathrm{~S}_{5}$ solid electrolytes and the thickness of the Au thin film was about $100 \mathrm{~nm}$.

XRD patterns of the $\mathrm{Au}$ thin films after vacuum-evaporation of $\mathrm{Li}$ on the electrolyte are shown in Fig. 6 (a). Diffraction peaks assigned to $\operatorname{Li}_{15} \mathrm{Au}_{4}$ alloy, which is the most lithiated phase in Li-Au alloys [17], were observed. The amount of $\mathrm{Li}$ deposited by vacuum-evacuation was excess above the amount of $\mathrm{Li}$ used for forming $\mathrm{Li}_{15} \mathrm{Au}_{4}$ alloy. Thus, diffraction peaks assigned to Li metal were also observed in Fig. 6 (a). The intensity of diffraction peaks of Li metal was much lower than that of the $\mathrm{Li}-\mathrm{Au}$ alloy. The reason has not been clarified yet, but it may be based on the difference of atomic scattering factors for X-ray between $\mathrm{Li}$ and $\mathrm{Au}$ [18]. Galvanostatic cycling tests for the $\mathrm{Li} / \mathrm{Au} / 75 \mathrm{Li}_{2} \mathrm{~S} \cdot 25 \mathrm{P}_{2} \mathrm{~S}_{5} / \mathrm{Au} / \mathrm{Li}$ cell are shown in Fig. 6 (b). At the initial cycle, the Li dissolution/deposition time of the cell was about 3.5 hours $\left(800 \mathrm{mC} \mathrm{cm}^{-2}\right)$, corresponding to about $0.0453 \mathrm{mg}$ of $\mathrm{Li}$ dissolution/deposition (about 35\% of $\mathrm{Li}$ 
utilization). Furthermore, about $25 \%$ of utilization of Li metal was retained after the $5^{\text {th }}$ cycle. Figure 7 shows the impedance plots of the $\mathrm{Li} / \mathrm{Au} / 75 \mathrm{Li}_{2} \mathrm{~S} \cdot 25 \mathrm{P}_{2} \mathrm{~S}_{5} / \mathrm{Au} / \mathrm{Li}$ cell (a) before galvanostatic tests, and (b) after the tests at the negative potential direction (i) and at the positive potential direction (ii). The resistance of the cell with Au thin films was lower than that of the cell without Au thin films (shown in Fig. 3) after the initial galvanostatic test at the negative potential direction. In addition, the interfacial resistance between $\mathrm{Li}$ metal and $\mathrm{Li}_{2} \mathrm{~S}-\mathrm{P}_{2} \mathrm{~S}_{5}$ solid electrolytes with characteristic frequency of $250 \mathrm{kHz}$ disappeared for the cell with Au thin films. These results indicate that a $\mathrm{Li}-\mathrm{Au}$ alloy layer prevented the generation of voids at the interface between $\mathrm{Li}$ thin film and $\mathrm{Li}_{2} \mathrm{~S}-\mathrm{P}_{2} \mathrm{~S}_{5}$ solid electrolytes where $\mathrm{Li}$ dissolution reaction occurred.

Figure 8 shows SEM images for cross-section and surface of the cell with Au thin films after galvanostatic cycling tests. The morphology of $\mathrm{Li}$ metal after $\mathrm{Li}$ dissolution/deposition reaction became more uniform compared to the cell without $\mathrm{Au}$ thin films as shown in Fig. 4. In the cell with Au thin films, voids at the interface between $\mathrm{Li}$ thin film and $\mathrm{Li}_{2} \mathrm{~S}-\mathrm{P}_{2} \mathrm{~S}_{5}$ solid electrolyte would not be generated during $\mathrm{Li}$ dissolution reaction because $\mathrm{Li}-\mathrm{Au}$ alloy remained at the interface after the dissolution reaction. The remained Li-Au alloy will functioned as the sites for next Li deposition. More uniform deposition in the cell with Au thin films may be caused by the increase of 
Li deposition sites. Detailed investigations are needed for clarifying the reasons of such great morphology change of Li metal by inserting Au thin films. The reversibility of Li dissolution/deposition for the cell with $\mathrm{Au}$ thin films is not a sufficient level for application, and thus optimizing the thickness of alloy layers and controlling the surface morphology of solid electrolyte layers are important for further improvement of uniform dissolution/deposition and its reversibility. The use of other metals which form Li alloy is also considerable for finding the most compatible Li alloy with sulfide electrolytes, and this trial is now in progress. It is noteworthy that homogeneous Li dissolution/deposition reaction occurred by inserting $\mathrm{Au}$ thin film between Li thin film and $\mathrm{Li}_{2} \mathrm{~S}-\mathrm{P}_{2} \mathrm{~S}_{5}$ solid electrolytes.

\section{Conclusion}

Bulk-type cells were fabricated using thin $\mathrm{Li}$ metal films prepared by vacuum-evaporation instead of $\mathrm{Li}$ foils in order to evaluate ideal interfaces between $\mathrm{Li}$ metal and $\mathrm{Li}_{2} \mathrm{~S}-\mathrm{P}_{2} \mathrm{~S}_{5}$ solid electrolytes. Symmetric cells with only Li thin films showed a high utilization of Li metal (about 40\%), though abrupt decrease of utilization was observed and the utilization was about $3 \%$ at the $5^{\text {th }}$ cycle. The morphology of Li thin films became rough after 5 cycles and the morphology change may be accelerated by 
the generation of voids at the interface between $\mathrm{Li}$ metal and $\mathrm{Li}_{2} \mathrm{~S}_{-} \mathrm{P}_{2} \mathrm{~S}_{5}$ solid electrolytes after the lithium dissolution reaction.

The effects of the insertion of $\mathrm{Au}$ thin films on $\mathrm{Li}$ dissolution and deposition properties were investigated. A high utilization of Li metal (about 25\%) was retained for 5 cycles by inserting Au thin film at the interface between Li metal and $\mathrm{Li}_{2} \mathrm{~S}-\mathrm{P}_{2} \mathrm{~S}_{5}$ solid electrolytes, indicating stable Li dissolution/deposition reactions occurred. It is revealed that inhomogeneous Li dissolution/deposition reactions occurred to the bulk-type cells with high utilization of $\mathrm{Li}$ metal. Insertion of $\mathrm{Au}$ thin films between Li metal and solid electrolytes was effective in retaining stable Li dissolution and deposition.

\section{Acknowledgement}

This research was financially supported by the Japan Science and Technology Agency (JST), Advanced Low Carbon Technology Research and Development Program (ALCA), Specially Promoted Research for Innovative Next Generation Batteries (SPRING) Project.

\section{References}

[1] J.M. Tarascon, M. Armand, Nature 414 (2001) 359-367. 
[2] U. Von Sacken, E. Nodwell, A. Sundher, J. R. Dahn, J. Power Sources 54 (1995) 240-245.

[3] http://www.excellatron.com/advantage.htm.

[4] J.B. Bates, N.J. Dudney, G.R. Gruzalski, R.A. Zuhr, A. Choudhury, C.F. Luck, J. Power Sources 43-44 (1993) 103-110.

[5] B. Wang, J.B. Bates, F.X. Hart, B.C. Sales, R.A. Zuhr, J.D. Robertson, J. Electrochem. Soc. 143 (1996) 3203-3213

[6] J.B. Bates, G.R. Gruzalski, N.J. Dudney, C.F. Luck, X. Yu, Solid State Ionics 70-71 (1994) 619-628.

[7] K. Kanehori, K. Matsumoto, K. Miyauchi, T. Kudo, Solid State Ionics 9-10 (1983) $1445-1448$

[8] S.D. Jones, J.R. Akridge, J. Power Sources 54 (1995) 63-67.

[9] M. Tatsumisago, A. Hayashi, Int. J. Appl. Glass Sci. 5 [3] (2014) 226-235.

[10] M. Tatsumisago, A. Hayashi, Solid State Ionics 225 (2012) 342-345.

[11] A. Hayashi, S. Hama, F. Mizuno, K. Tadanaga, T. Minami, M. Tatsumisago, Solid State Ionics 175 (2004) 683-686.

[12] A. Sakuda, A. Hayashi, M. Tatsumisago, Sci. Rep. 3 (2013) 2261.

[13] M. Nagao, A. Hayashi, M. Tatsumisago, Electrochem. Commun. 22 (2012) 
177-180.

[14] M. Nagao, A. Hayashi, M. Tatsumisago, Electrochemistry 80(10) (2012) 734-736.

[15] K. Okita, K. Ikeda, H. Sano, Y. Iriyama, H. Sakaebe, J. Power Sources 196 (2011)

$2135-2142$.

[16] M. Hiratani, K. Miyauchi, T. Kudo, Solid State Ionics 28-30 (1988) 1406-1410.

[17] A.D. Pelton, Bulletin of Alloy Phase Diagrams 7(3) (1986) 228-231.

[18] P. J. Brown, A.G. Fox, E.N. Maslen, M.A. O’Keefe, B.T.M. Willis, International Tables for Crystallography Vol. C, Kluwer Academic Publishers (2004). 


\section{Figure Captions}

Fig. 1 Cross-sectional SEM image of the interface between a $\mathrm{Li}$ thin film and $\mathrm{Li}_{2} \mathrm{~S}-\mathrm{P}_{2} \mathrm{~S}_{5}$ solid electrolytes.

Fig. 2 Galvanostatic cycling tests for Li symmetric cells.

Fig. 3 Impedance plots of Li symmetric cells (a) before galvanostatic tests, and (b) after the tests at the negative potential direction (i) and at the positive potential direction (ii).

Fig. 4 SEM images of cross-section and surface of Li symmetric cells before and after galvanostatic cycling tests

Fig. 5 Cross-sectional SEM image of the interface between $\mathrm{Au}$ thin film and $\mathrm{Li}_{2} \mathrm{~S}-\mathrm{P}_{2} \mathrm{~S}_{5}$ solid electrolytes.

Fig. 6 (a) XRD patterns of $\mathrm{Li} / \mathrm{Au}$ thin films on the $\mathrm{Li}_{2} \mathrm{~S}_{-} \mathrm{P}_{2} \mathrm{~S}_{5}$ solid electrolytes and (b) galvanostatic cycling tests for the Li symmetric cell inserting Au thin film.

Fig. 7 Impedance plots of the $\mathrm{Li} / \mathrm{Au} / 75 \mathrm{Li}_{2} \mathrm{~S} \cdot 25 \mathrm{P}_{2} \mathrm{~S}_{5} / \mathrm{Au} / \mathrm{Li}$ cell (a) before galvanostatic tests, and (b) after the tests at the negative potential direction (i) and at the positive potential direction (ii).

Fig. 8 SEM images for cross-section and surface of the cell with Au thin film after galvanostatic cycling tests. 
Figure(s)

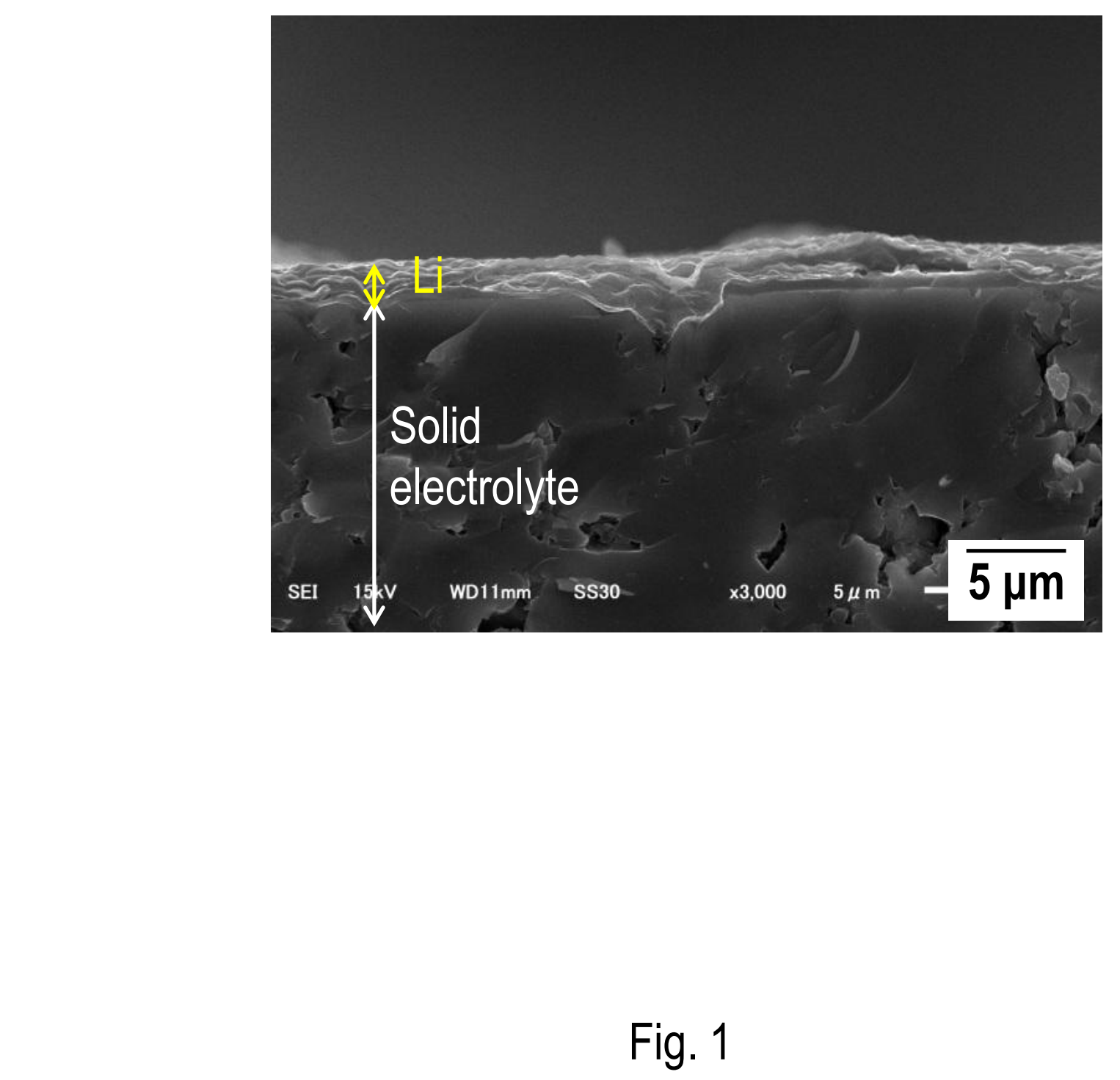

Fig. 1
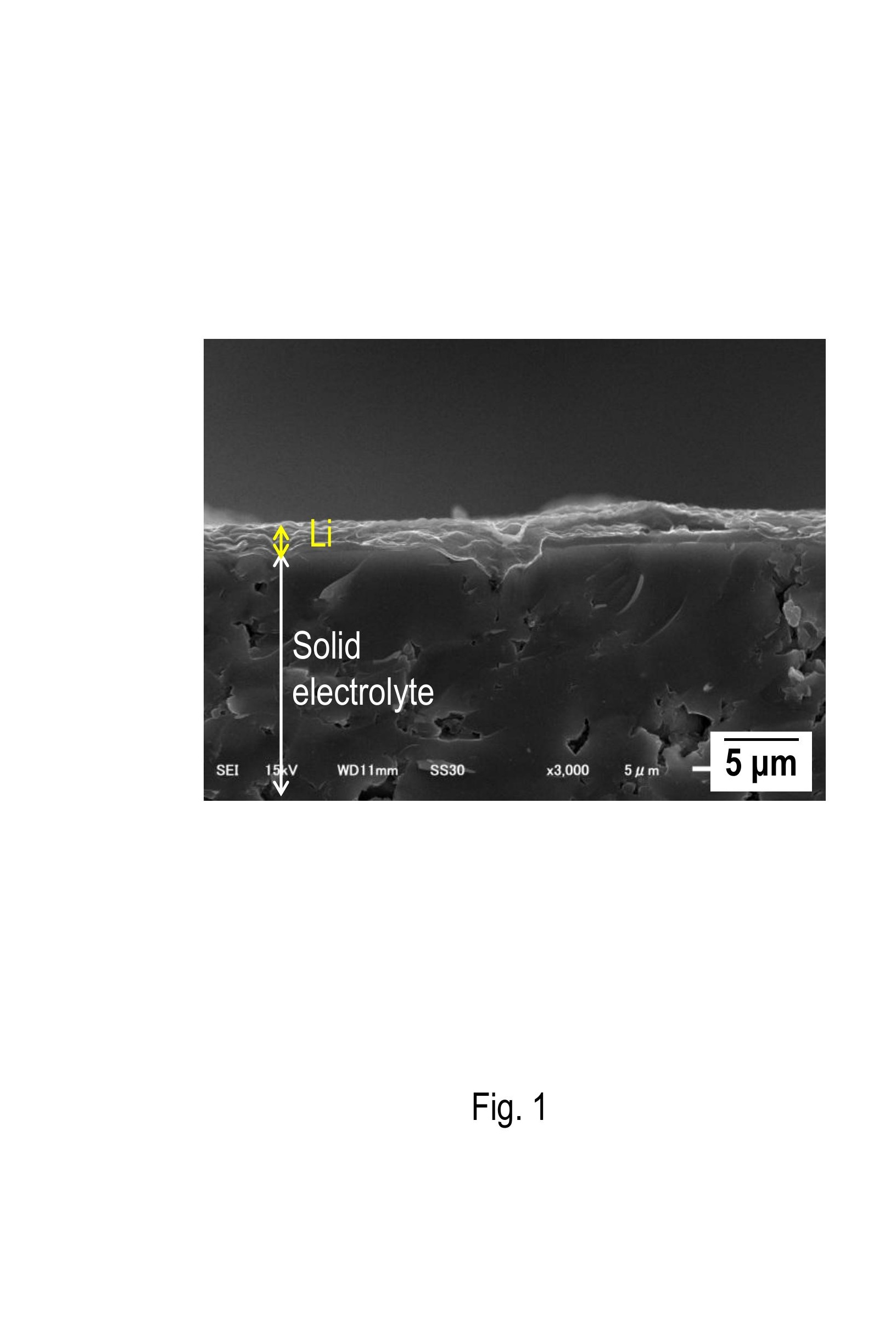

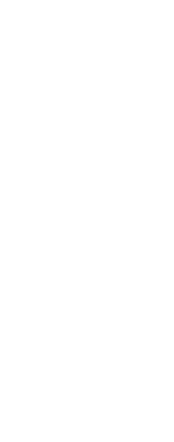




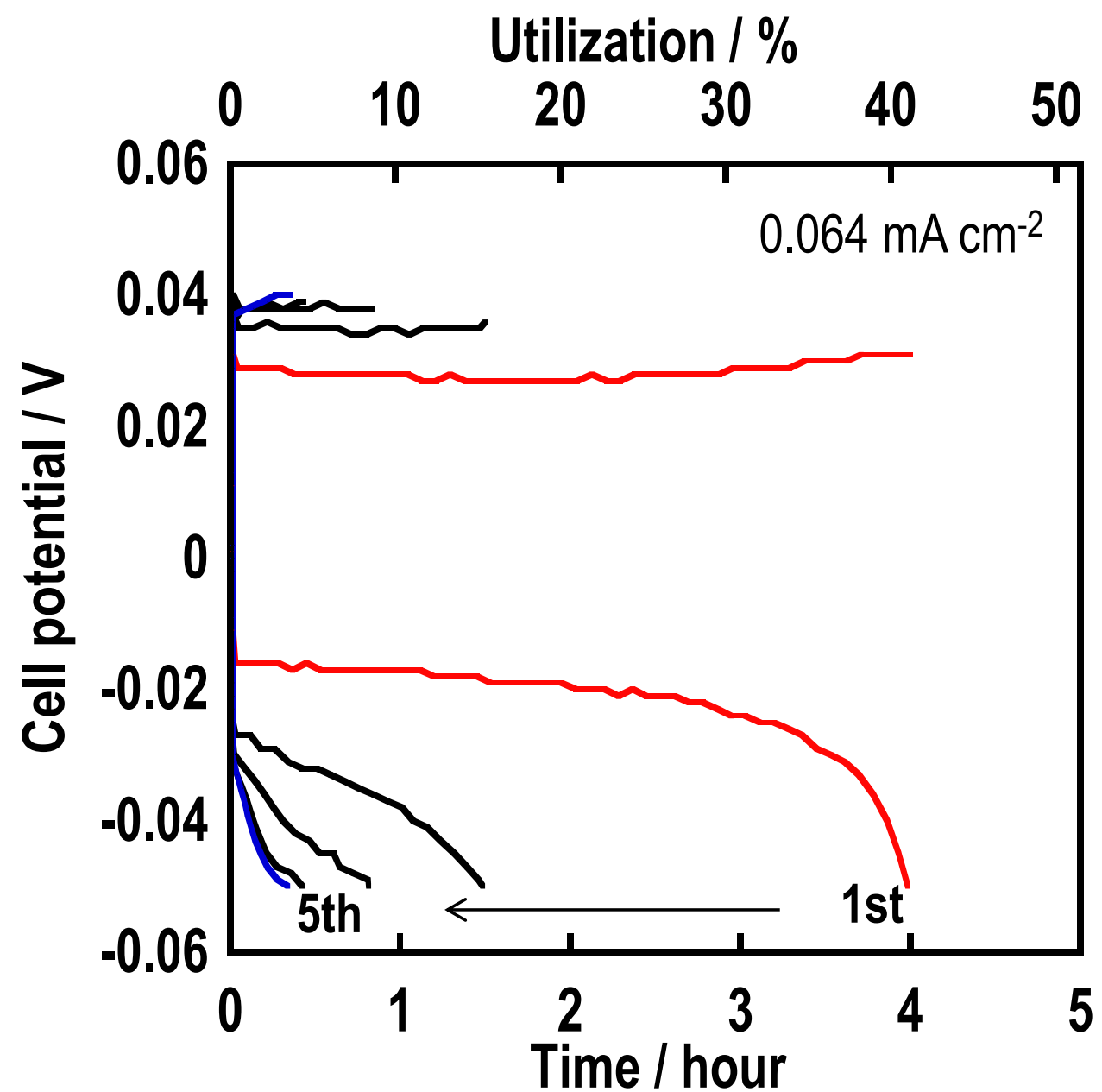

Fig. 2 

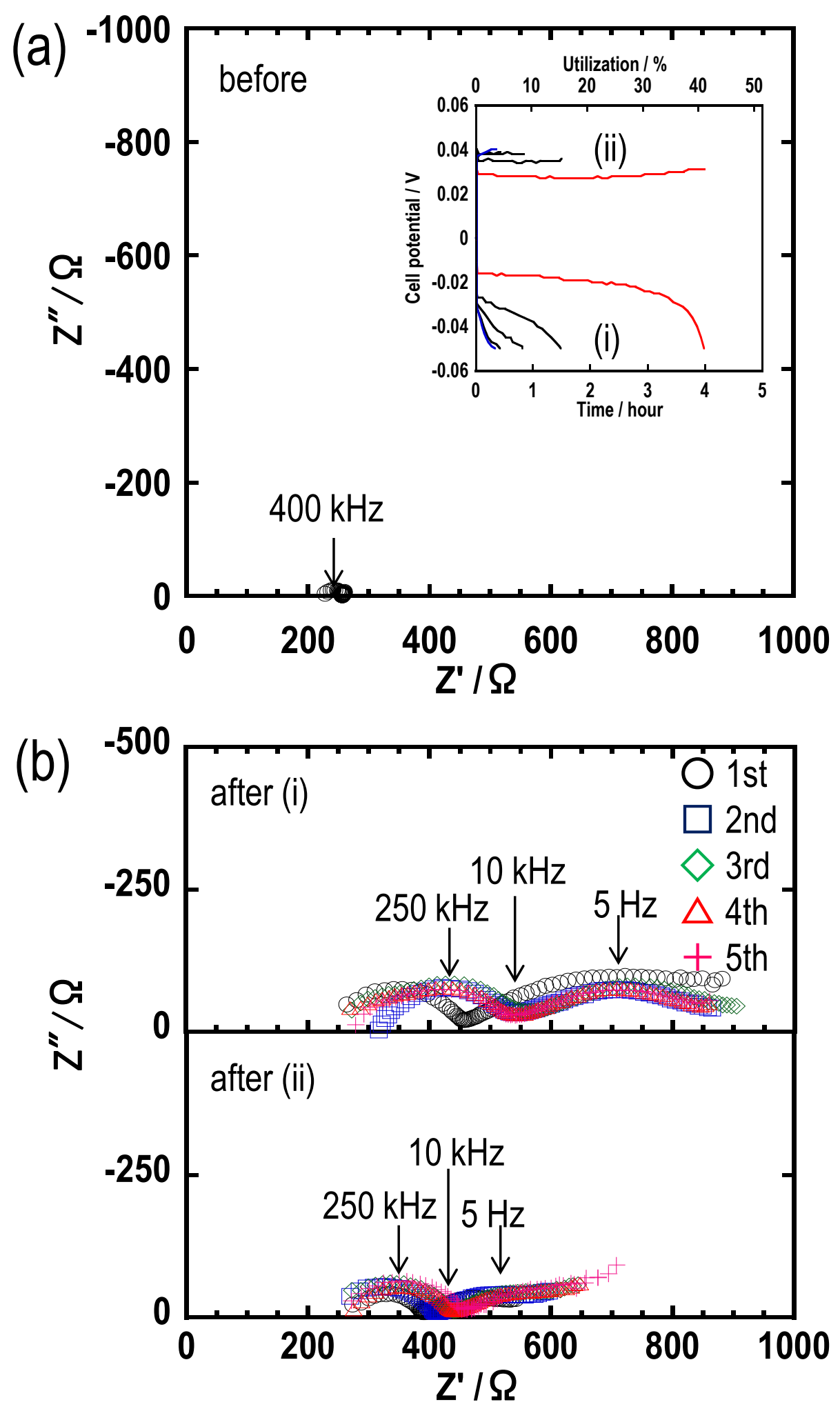

Fig. 3 


\section{before}
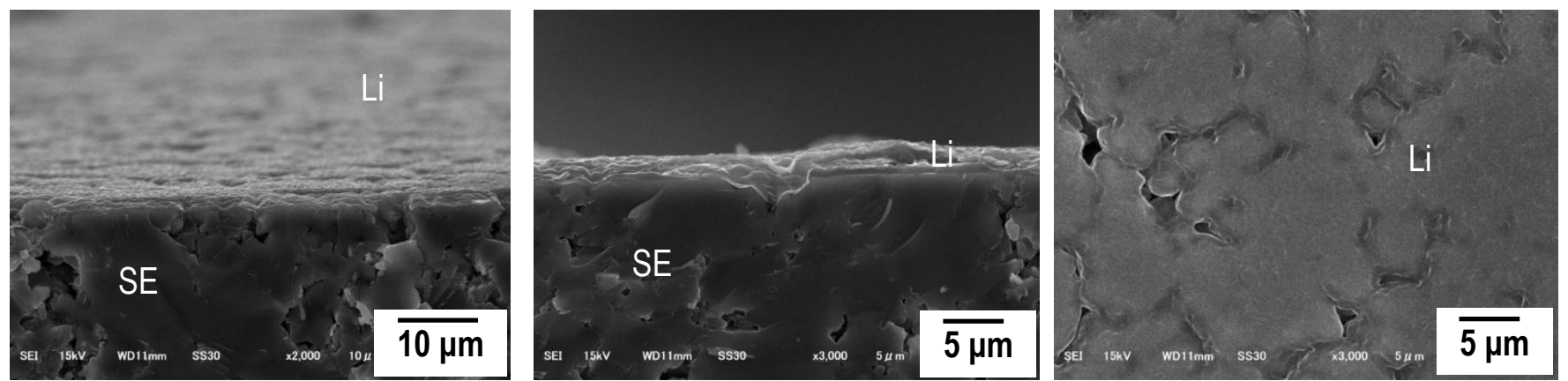

after galvanostatic cycling tests
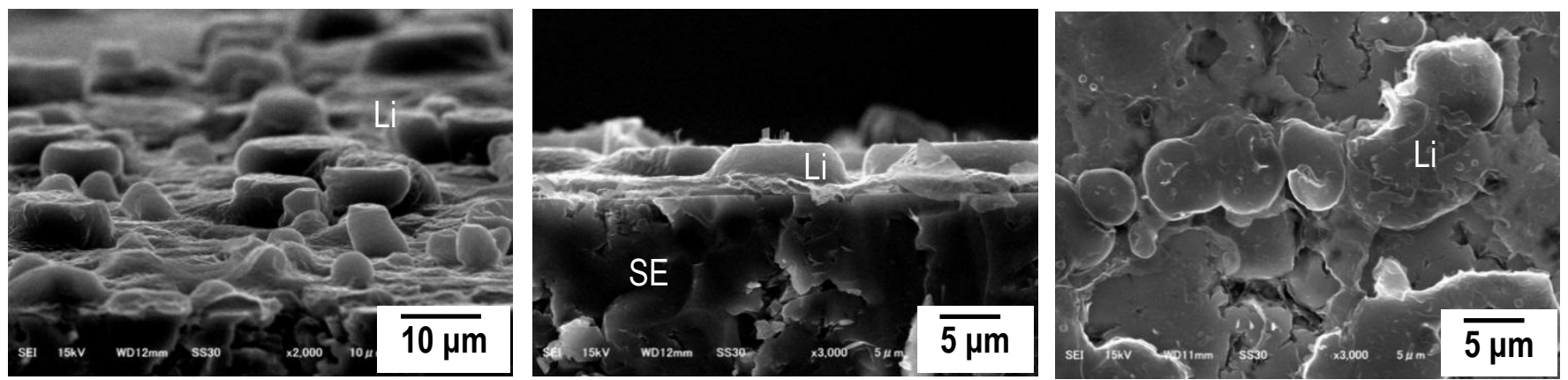

Fig. 4 
$\mathrm{Au}$

Solid electrolyte

\section{$\overline{500 \mathrm{~nm}}$}

Fig. 5 
(a)
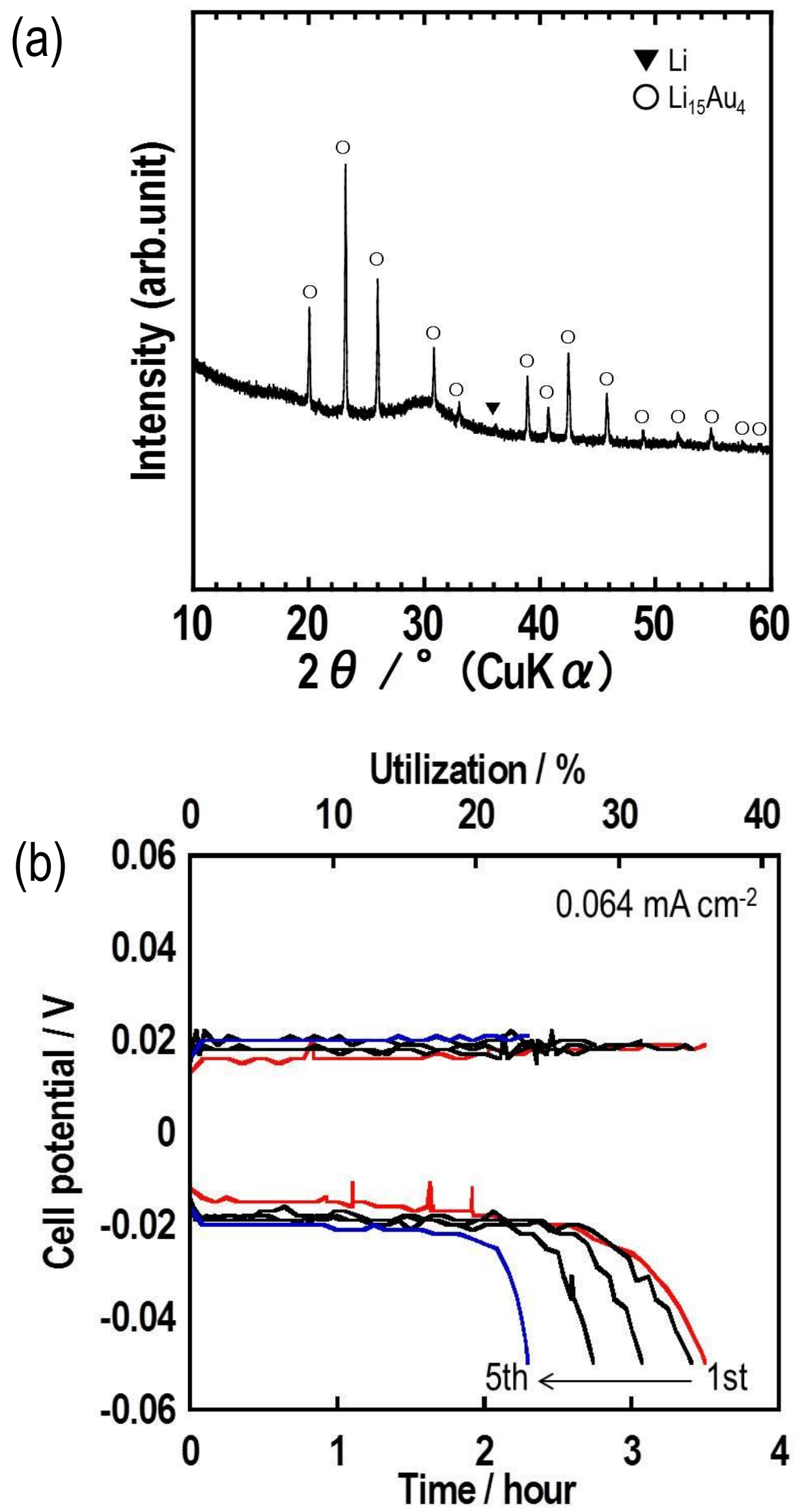

Fig. 6 

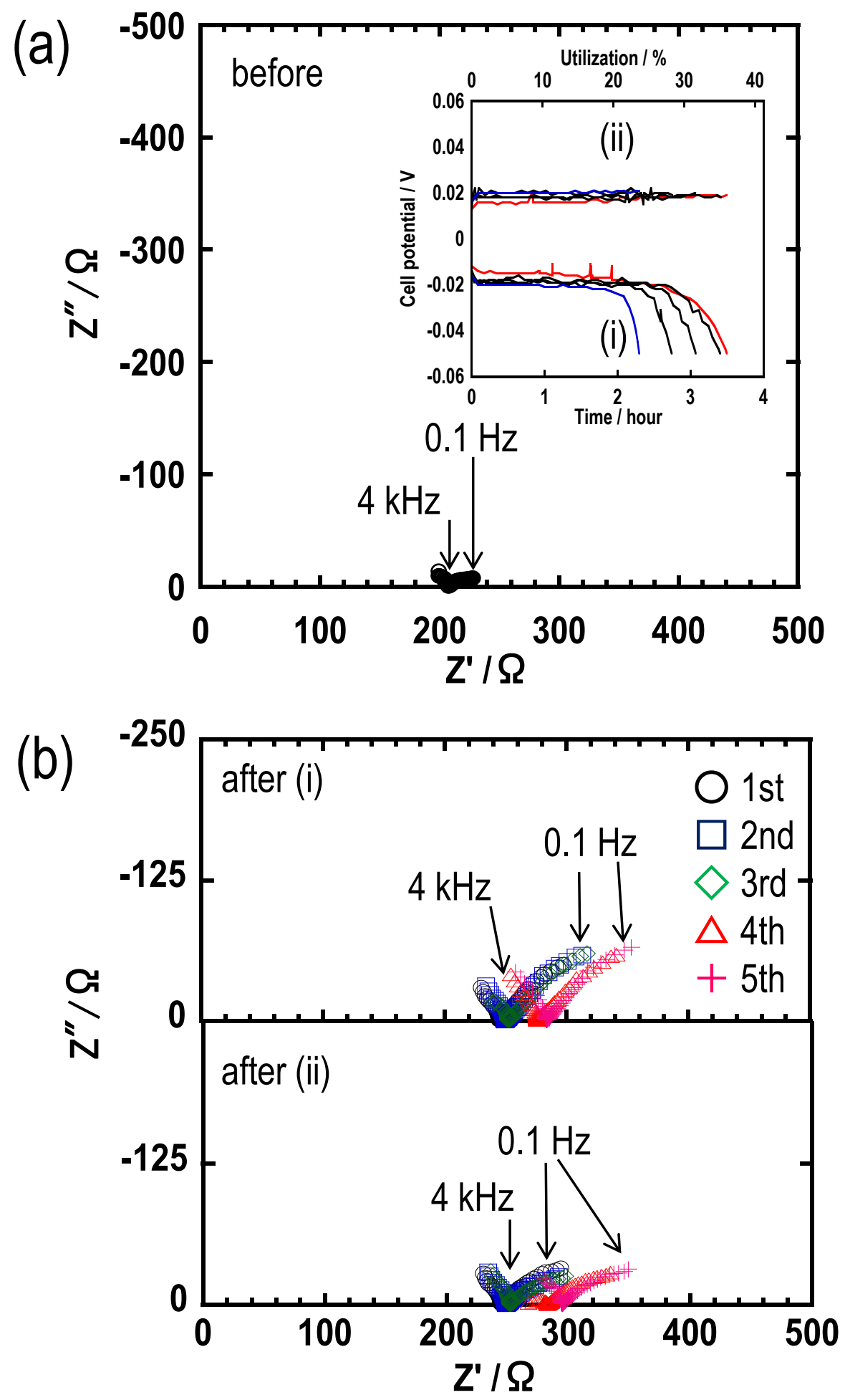

Fig. 7 

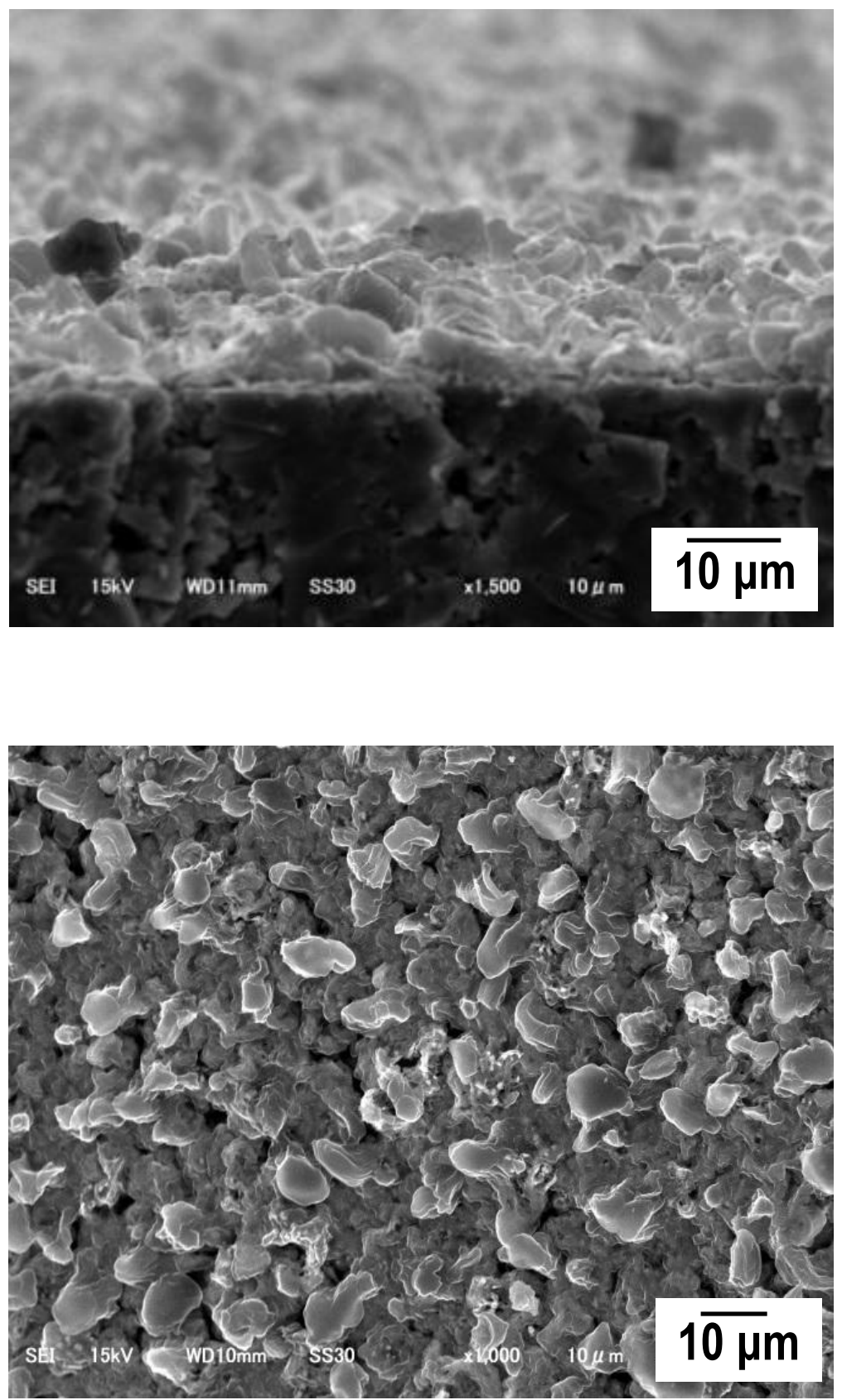

Fig. 8 